\title{
ПРИНЩИПИАЛЬНАЯ ВАЖНОСТЬ УЧЕТА СКОРОСТНЫХ НЕОДНОРОДНОСТЕЙ ВЧР В ПЛАТФОРМЕННЫХ УСЛОВИЯХ ОРЕНБУРГСКОЙ ОБЛАСТИ.
}

Калинин А.Ю., Черваков В.М.

\section{(ОАО «Оренбураская геофизическая экспедиция»)}

Теоретическими и экспериментальными исследованиями доказано, что качество, надежность и достоверность сейсмических временных разрезов в значительной степени определяются корректностью расчета статических поправок, учитывающих изменчивость верхней части разреза, особенно в платформенных условиях, где структуры имеют небольтие временные аномалии. К таким малоамплитудным, имеющим небольшие размеры и доступным в глубинном плане структурам в Оренбуржье не ослабевает интерес со стороны Заказчика. Поскольку на подобньх структурах открыт ряд высоко дебетныт месторождений.

Как известно, разнообразие типов строения верхней части разреза (ВЧР) привело к разработке многих способов изучения распределения скоростей в поверхностных отложениях, необходимых для определения априорных поправок до уровня приведения. Но обоснованность выбора методик применительно к существующей сейсмогеологической ситуации является важным условием всего геофизического процесса. Определение и коррекция статических поправок были и остаются одними из основных процедур обработки сейсмических материалов в методе отраженных волн.

$\mathrm{He}$ секрет, что короткопериодные составляюшие аномальных временных сдвитов с хорошей точностью корректируются при обработке данных МОГТ. Определение средне- и длиннопериодных поправок - это, по существу, проблема разделения поверхностного и структурного факторов, которая не всегда может быть решена по самим сейсмическим данным и требует привлечения дополнительной исходной информации о поверхностных и глубинных условиях. Все это может привести даже к необходимости проведения специальных исследований в этом направлении.

Целью проведенной работы являлся анализ влияния скоростных неоднородностей ВЧР на глубинное волновое поле на примере одной из плошадей, расположенной в платформенных условиях Оренбургской области.

Данная плошадь работ отработана методом общей глубинной точки в модификации $3 Д$. Район исследований характеризуется значительной расqлененностью рельефа местности. Абсолютные отметки колеблются в пределах от 112 до 300 метров. Верхняя часть разреза сложно построена и представлена зоной малых и зоной пониженных скоростей, мощности и скорости в которых изменяются в широких пределах. Поведение подошвы зоны мапых скоростей, как правило, не соотвепствует поведению рельефа. Такие сложные условия и обусловили проведение специальных исследований для изучения скоростных неоднородностей верхней части разреза методом преломленных волн по сети пунктов зондирования $900 \times 900 \mathrm{M}$.

Основываясь на анализе построенных вре- менных карт по основным отражающим горизонтам, сечений куба данных, который обработан с различными априорными статическими поправками, были оценены влияние скоростных неоднородностей на глубинное волновое поле и сделаны рекомендации для производства дальнейших полевых работ в аналогичных условиях.

Результаты проведенной работы свидетельствуют о принципиальной важности выбора методики учета статических поправок еще на этапе проектирования сейсморазведочных работ, основываясь на геологическом анализе не только данных МОГТ, но и информации по верхней части разреза. 